\title{
Testing wirelessly-monitored thermometers for improved patient safety
}

\author{
Karen Alston ${ }^{1}$, Radka Veltcheva ${ }^{1}$ and Angela Gallego ${ }^{2}$ \\ ${ }^{1}$ National Physical Laboratory, Teddington, Middlesex, UK \\ ${ }^{2}$ Isansys Lifecare Ltd, Milton Park, Oxfordshire, UK
}

\begin{abstract}
We describe the metrological characterisation of temperature measurements performed by a wireless patient surveillance system developed by Isansys, which allows healthcare providers to remotely monitor a patient's vital signs even after they have left the hospital. The system collects and analyses patient data, such as temperature, heart rate and respiration rate, alerting healthcare providers if it detects the early signs of sepsis - a condition which kills 37,000 patients in the UK annually.
\end{abstract}

\section{Introduction}

The National Physical Laboratory (NPL) has combined its expertise and facilities in temperature and humidity measurement to calibrate and assess the performance of a wirelessly monitored clinical thermometer (Lifetemp) for healthcare company, Isansys Lifecare.[1]

Isansys Lifecare Ltd has created a continuously operating vital sign data acquisition, analysis and prediction platform called "the Patient Status Engine" (PSE). This combines unobtrusive wireless wearable sensors, wireless networks, analytical algorithms and 'big data' to provide monitoring for patients in hospital and at home.

This patient monitoring system performs observations of heartbeat, breathing, and oxygen saturation every second, temperature every minute and blood pressure as required.

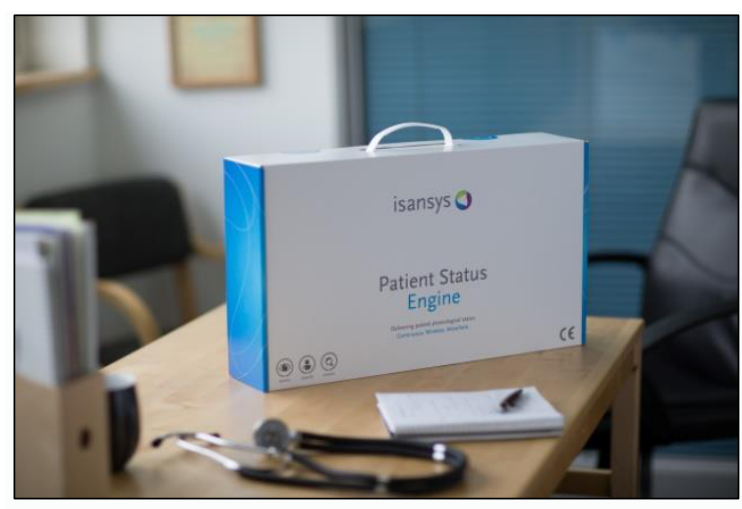

Figure 1. Patient Status Engine (PSE)

${ }^{a}$ Corresponding author: Radka. Veltcheva@npl.co.uk
Wirelessly-readable thermometers need to perform consistently as the wearer's surroundings change and they require accurate calibration in a range of different environments. The calibrated clinical thermometer is a thermistor connected to an electronic module, which transmits the data wirelessly to a tablet or smartphone.

In accordance with the requirements of the standard BS EN ISO 80601-2-56:2012 [2], the thermometer was calibrated at a series of fixed temperatures over a range of ambient temperatures (from $15{ }^{\circ} \mathrm{C}$ to $35^{\circ} \mathrm{C}$ ) and humidities (from $20 \% \mathrm{rh}$ to $80 \% \mathrm{rh}$ ). The temporal response of the device to applied heating and cooling was also measured.

\section{Experiment}

The clinical thermometer consists of a $5 \mathrm{~mm}$ long, $3 \mathrm{~mm}$ outer diameter thermistor connected to an electronic readout module by a pair of wires $75 \mathrm{~mm}$ in length. The module sends a signal to a remotely located tablet every second. Specially designed software converts the signal to temperature which is displayed and saved in the database.

The thermistor was placed in the thermometer well of a dry block calibrator to a depth of $75 \mathrm{~mm}$ together with a traceably calibrated reference thermometer. The unit was tested by comparison of the displayed temperatures with those of the reference thermometer. The clinical thermometer was tested at $25.5^{\circ} \mathrm{C}, 35^{\circ} \mathrm{C}$ and $44.5^{\circ} \mathrm{C}$. All three temperatures were realized in different environmental conditions as follows:

- Ambient temperature of $25.5^{\circ} \mathrm{C}$ and humidity of $50 \%$ rh;

- $\quad$ Ambient temperature of $15.5^{\circ} \mathrm{C}$ and humidities of $20 \%$ rh and $80 \%$ rh;

- Ambient temperature of $35.5^{\circ} \mathrm{C}$ and humidities of $20 \%$ rh and $80 \%$ rh. 
To create the required environment, the dry block calibrator, including the standard reference thermometer and the clinical thermometer, were placed into an environmental chamber. For each condition, the chamber was set to provide the required humidity and temperature. The measurements were performed once stable environmental conditions were reached. The chamber temperature was stable within $\pm 0.5{ }^{\circ} \mathrm{C}$ and the humidity was stable within $\pm 5 \%$ rh. Temperature and humidity in the chamber were measured using a calibrated hygrometer. Results of measurements are shown in Table 1. The standard BS EN ISO 80601-256:2012 states that during the test the clinical thermometer must show no error greater than $0.3^{\circ} \mathrm{C}$.

To test the temporal response, the thermometer was placed in the water bath controlled at a stable temperature of $35^{\circ} \mathrm{C}$ (T1). Once thermal equilibrium was achieved the thermometer was moved immediately to the dry block calibrator. The temperature of the dry block calibrator was controlled at $37{ }^{\circ} \mathrm{C}$ and $33{ }^{\circ} \mathrm{C}$ (T2) to monitor warming and cooling respectively. The temporal response was defined as a time taken by the unit under test (UUT) to reach $90 \%$ of the final temperature. The measurement setup is shown in Figure 2.

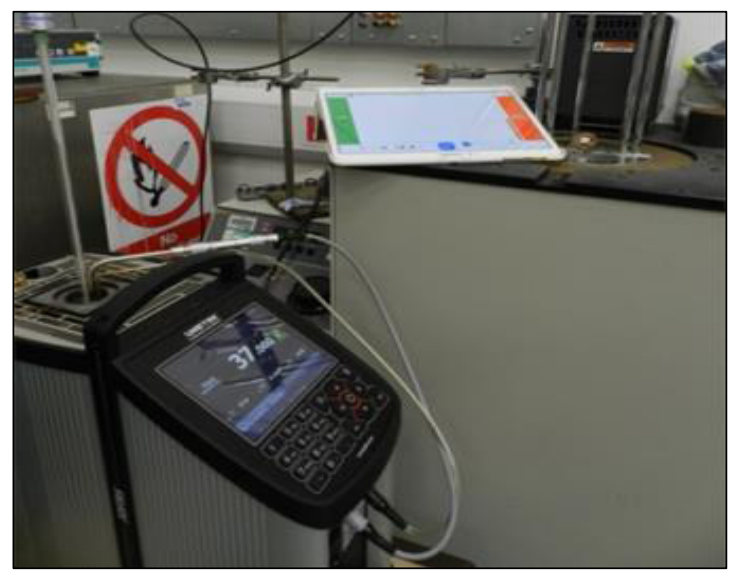

Figure 2. Measurement setup for measuring temporal response

\section{Results}

The results of the test are set out in the following tables, where the corrections which show the difference between the ITS-90 temperature and the displayed temperature are stated to the nearest $0.1{ }^{\circ} \mathrm{C}$ and represent the mean of the observations.

The temporal response of the clinical thermometer was measured as the thermometer was subjected to a step change between the two temperatures several times. An average of the measured time is recorded in the Table 2.

The temperature of the dry block calibrator was measured by the reference thermometer with an estimated uncertainty of $\pm 0.04{ }^{\circ} \mathrm{C}$. The uncertainty of the temperatures measured by the reference thermometer is $\pm 0.001^{\circ} \mathrm{C}$.

Table 1. Test results

\begin{tabular}{|c|c|c|c|}
\hline $\begin{array}{l}\text { Ambient } \\
\text { Temperature, } \\
{ }^{\circ} \mathrm{C}\end{array}$ & $\begin{array}{l}\text { Relative } \\
\text { Humidity, } \\
\% \text { rh }\end{array}$ & $\begin{array}{l}\text { Reference } \\
\text { Temperature, } \\
{ }^{\circ} \mathrm{C}\end{array}$ & $\begin{array}{l}\text { UUT } \\
\text { Reading, }{ }^{\circ} \mathrm{C}\end{array}$ \\
\hline \multirow{3}{*}{25} & \multirow{3}{*}{50} & 25.724 & 25.50 \\
\hline & & 34.965 & 34.86 \\
\hline & & 44.469 & 44.32 \\
\hline \multirow{6}{*}{35.5} & \multirow{3}{*}{20} & 25.443 & 25.26 \\
\hline & & 35.538 & 35.44 \\
\hline & & 44.459 & 44.50 \\
\hline & \multirow{3}{*}{80} & 25.440 & 25.31 \\
\hline & & 35.897 & 35.80 \\
\hline & & 44.458 & 44.50 \\
\hline \multirow{6}{*}{15.5} & \multirow{3}{*}{20} & 25.472 & 25.34 \\
\hline & & 34.977 & 34.86 \\
\hline & & 44.481 & 44.40 \\
\hline & \multirow{3}{*}{80} & 25.472 & 25.38 \\
\hline & & 34.975 & 34.84 \\
\hline & & 44.481 & 44.40 \\
\hline
\end{tabular}

Table 2. Temporal response

\begin{tabular}{|l|c|l|}
\hline & $\begin{array}{l}\text { Temperature step } \\
\text { change }\end{array}$ & $\begin{array}{l}\text { Temporal } \\
\text { response }\end{array}$ \\
\hline Heating time & $\begin{array}{r}\mathrm{T} 1=35^{\circ} \mathrm{C} \\
\mathrm{T} 2=37^{\circ} \mathrm{C}\end{array}$ & 15 seconds \\
\hline Cooling time & $\mathrm{T} 1=35^{\circ} \mathrm{C}$ & 11 seconds \\
& $\mathrm{T} 2=33^{\circ} \mathrm{C}$ & . \\
\hline
\end{tabular}

The uncertainty at the time of test is calculated as follows:

$U=\sqrt{U_{c t}^{2}+U_{R T}^{2}+U_{s t a b}^{2}+U_{h o m}^{2}}$

where

$U_{c t}$ is the uncertainty of clinical thermometer;

$U_{R T}$ is the uncertainty of reference thermometer;

$U_{\text {stab }}$ is the uncertainty due to the stability of the dry block and

$U_{h o m}$ is the uncertainty due to the uniformity of the dry block

The estimated uncertainty at the time of test is $\pm 0.2{ }^{\circ} \mathrm{C}$ and it is based on a standard uncertainty multiplied by a 
coverage factor $k=2$, providing a coverage probability of approximately $95 \%$.

\section{Conclusions}

Results from the performed test showed that the presented clinical thermometer is suitable for use as a part of Patient Status Engine (PSE). The tested clinical thermometer complies with the requirements of the standard "BS EN ISO 80601-2-56:2012 Particular requirements for basic safety and essential performance of clinical thermometers for body temperature measurements".

\section{Acknowledgements}

The authors thank the Humidity group at NPL for providing the facilities used for realization of the required environmental conditions

\section{References}

1. Isansys Lifecare, www.isansys.com

2. BS EN ISO 80601-2-56:2012 Particular requirements for basic safety and essential performance of clinical thermometers for body temperature measurements 